\title{
KIMBERLITE OLIVINES
}

A.E. MOORE

GEOLOGICAL SUPPORT SERVICES, BOX 10072, GABORONE, BOTSWANA

\section{INTRODUCTION}

Olivine dominates the phenocryst assemblage in kimberlites. Compositional variation of this phase should therefore mirror chemical evolutionary paths of the host magma. Also, it has been suggested (e.g. Bailey, 1984) that kimberlites are hybrid rocks, significantly contaminated by dissociated mantle xenoliths. A study of kimberlite olivines should place constraints on the proportion of such exotic material present. This in turn has important bearing on the chemical character of kimberlite magmas. Of particular concern is whether the high bulk rock Mgo content that characterizes kimberlites reflects an originally very Mgo-rich magma or substantial contamination of ahighly refined incompatible-rich magma by xenocrystic olivines.

Extremely fresh kimberlite samples were collected for study from the Letseng-laterai kimberlite, Lesotho, the deBeers and Newlands pipes in the Kimberley area, and two pipes from the Gibeon district, Namibia. These represent kimberlite clusters on an East - West transect across southern Africa. According to the classification of Smith (1983), the Newlands pipe belongs to the Type II group of kimberlites, while the others studied fall into his type I group. For comparitive purposes, a study was also made of olivines in a very fresh sample from the Hamilton Branch kimberlite, U.S.A.

\section{PETROGRAPHY}

Between two and six thin sections were examined for each of the kimberlites studied. In these samples, virtually all of the olivines occur as discrete grains. Orthopyroxene, garnet and other mantle-derived minerals are extremely rare or absent in the thin sections studied, either as discrete grains or as intergrowths with olivine.

Superficial examination of the thin sections suggests that kimberlite olivines group into two dominant populations: (i) Large grains with rounded margins (macrocrysts) and (ii) small euhedral to subhedral crystals. In some of the specimens studied (e.g. de Beers), many though not all, of the large olivines show undulose extinction or sub-grain optical domains indicating recrystallization. In such cases however, both undulose extinction and sub-grain crystallographic domains also occur in some of the associated euhedral olivines of the second population. In contrast, in the Newlands kimberlite, both types of olivine are entirely strain free. In all samples, some of the large rounded olivines extinguished parallel to long edges, possibly relict rational crystal faces.

To place constraints on the possible occurrence of two distinct olivine populations in kimberlites, longest axes of all grains greater than $0,25 \mathrm{~mm}$ were measured in two thin sections (total area roughly $1800 \mathrm{~mm}^{2}$ ) from the deBeers kimberlite and four thin sections (total area roughly $3600 \mathrm{~mm}^{2}$ ) from the Newlands sample. Surprisingly, these data suggest a continuous size variation rather than two distinct populations. (Fig. 1)

\section{CHEMISTRY}

In each kimberlite sample studied, olivines were subjectively divided according to decreasing size into four groups: (i) Large, (ii) Intermediate-sized, (iii) small and (iv) micro-olivines. The first two catagories would include the macrocrysts, while the euhedral to subhedral olivines would fall into the third and fourth.

Between 70 to 100 electron microprobe analyses of olivines were made in each of the kimberlites studied. At least two analyses (centre and edge) were made of individual olivines. The olivines from the different pipes have a fairly consistent pattern of chemical variation, broadly similar to that illustrated by the deBeers kimberlite.

(Fig. 2) 
Collectively, the centres of the large majority of the olivines define a single continuous field characterized by decreasing $\mathrm{Mg} /(\mathrm{Mg}+\mathrm{Fe})$ associated with a slight sympathetic decrease in $\mathrm{Ni}$. In general, the large and intermediate sized olivines are Mg-rich relative to small olivines and micro-olivines, although there is some overlap in the chemical fields of these different size groups. Edge compositions of all the olivines tend to be relatively Mg-poor, and define a field characterized by sharply decreasing $\mathrm{Ni}$.

In addition to the olivines constituting the dominant chemical field described above, there are rare individuals characterized by distinctly higher Fe and lower $\mathrm{Ni}$ contents. Most of the olivines with this distinctive chemical signature are rounded macrocrysts although some small euhedral olivines and micro-olivines may also be markedly Fe-rich and Ni-joor. This chemically distinct group of olivines has been recognised in all of the kimberlites studied, including the north American Hamilton Branch pipe.

\section{DISCUSSION}

The petrographic and chemical data presented suggest that most kimberlitic olivines belong to a single size and chemical population. As the euhedral olivines are undoubtedly cognate phenocrysts, any model for the origin of kimberlite magmas which requires that a substantial proportion of the olivines are xenocrysts must provide compelling evidence to substantiate such an exotic origin.

An alternative interpretation of the data presented is that the greater majority of kimberlite olivines are cognate phenocrysts. If valid, this would indicate an extended period of crystallization of the phase in the kimberlite magma, with the Mg-rich macrocrysts being the earliest formed crystals. Rounding of the macrocrysts may simply reflect their longer exposure to fluidization processes during magma ascent. Several lines of evidence lend support to this interpretation :

1. Orthopyroxene and pyrope xenocrysts are extremely rare in kimberlites. These phases would beexpected to be more common if a substantial proportion of the olivines in kimberlites are derived from disaggregated mantle xenoliths.

2. A. Harwood (kimberlite symposium, University of Cape Town, 1986) recognizes a temperature-related sequence of primary fluid inclusions in euhedral olivines in kimberlites. His initial data indicate that macrocryst olivines have primary fluid inclusions matching high temperature inclusions in the euhedral olivines. This suggests co-magmatic crystallization of these olivines.

3. Eggler and Wendlandt (1978) show that a rock corresponding to an average Lesotho kimberlite composition will have a liquidus temperature of $1450^{\circ} \mathrm{C}$ if the $\mathrm{CO}_{2} /\left(\mathrm{CO}_{2}+\mathrm{H}_{2} \mathrm{O}\right)$ ratio is 0,5 . This temperature closely matches the maximum palaeogeotherm temperatures recorded in mantle xenoliths from the Lesotho kimberlites (Nixon and Boyd, (1973), which presumably set minimum temperatures for the entraining magma. Much lower liquidus temperatures would be appropriate to kimberlites if a significant portion of the olivines are xenocrysts.

The origin of the Fe-rich and Ni-poor olivines that characterize all of the kimberlites studied is speculative, though appears to be intimately related to the processes responsible for kimberlite genesis. Chemically, they are analogous to the high iron, low nickel olivines described from olivine melilitites in Southern Africa (Moore and Erlank, 1979), possibly pointing to a genetic link between the two rock types.

Acknowledgements : Julian Hobbs is thanked for his critical comrnents, and Diana Evans for typing the abstract.

\section{References}

Bailey D.K. (1984) Developments in Petrology IIA (323-33). Elsevier. Eggler D.H. and Wendlandt R.F. (1978) Carnegie Inst. Wash. Yb 77 (751-6) Moore A.E. and Erlank A.J. (1979) Contrib. Min. Pet. 70 (391 - 405)

Nixon P.H. and Boyd F.R. (1973) Lesotho kimberlites (48 - 56)

Smith C.B. (1983) Nature 304 (51 - 54) 

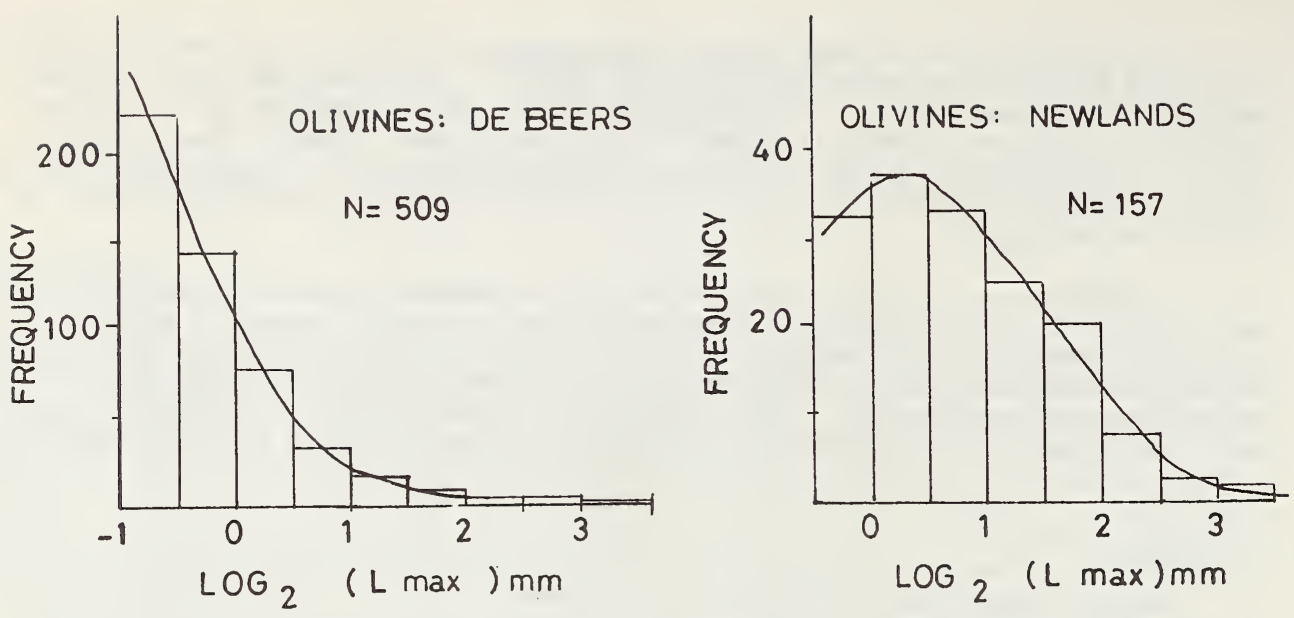

Fig 1. Histograms of longest axes ( $\mathrm{L} \max$ ) for all olivines greater than $0,5 \mathrm{~mm}$ in two thin sections (total area $=1800 \mathrm{~mm}^{2}$ ) from the deBeers kimberlite, and for thin sections (total area $=3600 \mathrm{~mm}^{2}$ ) from the Newlands pipe.



Fig 2. $\mathrm{Mg} /(\mathrm{Mg}+\mathrm{Fe})-\mathrm{Ni}$ plot for olivines from the deBeers kimberlite. Olivines are subjectively divided according to size into four groups :

1) Large (crosses); 2) Intermediate (triangles); 3) Small (open circles); 4) micro (solid circles). Squares denote edge compositions of all olivines. Dotted lines show core to margin variation for individual olivines. Note that with the exception of rare Fe-rich and Ni-poor grains, centres of all olivines analysed define a continuous field. Although there is some compositional overlap for the different size groups, the largest olivines are in general Mg-rich and the smallest crystals Mg-poor. 